\title{
Comparison of numerical modeling results from laboratory and field obtained unsaturated flow parameters
}

\author{
Asif Ahmed ${ }^{1}$, Md Jobair Bin Alam ${ }^{2}$, Md Azijul Islam ${ }^{3}$, and MD Sahadat Hossain ${ }^{4}$ \\ ${ }^{1}$ SUNY Polytechnic Institute, College of Engineering, 100 Seymour Road, Utica, NY 13502, USA \\ ${ }^{2}$ Prairie View A\&M University, Civil Engineering Department, 100 University Drive, Prairie View, TX 774466, USA ${ }^{3,4}$ University \\ of Texas at Arlington, Civil Engineering Department, 416 Yates Street, Arlington, TX 76019, USA
}

\begin{abstract}
Moisture and suction variation beneath pavement contribute significantly to the volumetric deformation of expansive subgrade in response to climatic loading. In order to quantify the damage due to climatic loading, estimation of moisture, and suction variation in pavement subgrade is of paramount importance. The objective of the current study is to investigate the moisture and suction variation in response to precipitation events with the aid of numerical modeling in the unsaturated pavement subgrade. In unsaturated soils where the voids are filled with both water and air, the SWCC describes the volume of the voids that remain filled with water as the soil drains pore water. The SWCC has been identified as the vital soil information required to analyze seepage, stability, and volume change problems involved in unsaturated soils. However, the selection of unsaturated flow parameters is typically laboratory-based which represents specific conditions rather than a dynamic scenario of the field. In this study, an attempt was undertaken to conduct numerical modeling using field generated unsaturated flow parameters along with five other predictive models. Results indicated the distinct variation of moisture and suction distribution in subgrade from the same rainfall event while using laboratory versus field generated SWCC unsaturated flow parameters. In addition, predicted model yielded output was also varying with the field generated parameters' output. Instead of using laboratory-generated static parameters, it was found that field generated dynamic unsaturated flow parameters were able to capture better suction variation at the pavement subgrade.
\end{abstract}

\section{Introduction}

Moisture variation in the expansive subgrade is one of the major causes of pavement distress in Texas, USA. Many researchers [1,2] have carried out the field-based analysis to correlate the subgrade soil characteristics and environmental factors in order to incorporate the variation of moisture in the design. Numerical modeling has appeared as a recent development in the process of providing additional information on volumetric deformation [3]. Based on an infinite slab and other idealized assumptions, the finite element method (FEM) can be used to analyse the effects of many practical conditions, which are more realistic than theoretical solutions [4].

Any soil can be characterized based on its soil water characteristics curve (SWCC), a unique property of each soil. SWCC depends on particle size distribution and pore space present in the soil. Currently practiced methods of determining SWCC such as pressure plate, Tempe cell, filter paper techniques [5], are time and labor-consuming and highly dependent on the operator as well. Zapata (2000) [6] has stated that there are a limited number of geotechnical laboratories which performs suction-based tests. In fact, the researchers have been using statistical analyses, physical tests, Artificial Neural Network (ANN), Genetic Programming (GP) to determine SWCC [5]. However, the accuracy of these analytical and predictive models is widely argued, introducing uncertainties in determining the unsaturated flow parameters $(\alpha, \theta \mathrm{r}, \theta \mathrm{s}, \mathrm{m}$, and $\mathrm{n})$. Hernandez et al. (2019) [7] showed that the predictive models could lead to over two orders of magnitude difference in the value of $\alpha, 1.25$ to 2.85 times higher values of $n$, and 0.06 to 0.21 times lower ratios of $\theta \mathrm{r}$ to $\theta \mathrm{s}$ compared to those determined from the laboratory assessments. These differences can lead to significant variations in the numerical analysis of the expansive behavior of pavement subgrade soils, a factor that needs to be carefully taken into consideration.

Hedayati (2014) [5] studied both unsaturated moisture diffusion and volume change in an expansive subgrade. Hasem et al. (2013) [8] simulated the behavior of flexible pavement construction on expansive soil using numerical modeling by Plaxis 2D software. Djellali et al. (2012) [9] concluded that the combined Mohr-Columb Model and soft soil model showed the majority of displacements in the pavement of Algeria taking place in the shoulder side of the pavement after the numerical modeling analysis. Generally, there is a trend of using the laboratory tested values in numerical modeling since the field-based values 
are difficult to access. However, the use of such soil parameters will consider just the specific condition at which the laboratory testing is conducted. As such, it does not take into consideration the external factors such as climatic factors; consequently, there is less chance of fully understanding the actual behavior of the pavement built on expansive soil. Therefore, the use of field-based soil parameters in numerical modeling is a necessity as well as a challenge. In the current study, numerical modeling of expansive subgrade pavement was conducted using SEEP/W incorporating unsaturated parameters obtained from previous prediction models, laboratory, and field generated SWCC parameters. The modeling output is compared and discussed based on the suction value obtained after the precipitation events.

\section{Materials and Method}

\subsection{SWCC}

An assessment of the soil water characteristic curve (SWCC) is required to evaluate the water flow parameters at different saturation conditions. The SWCC describes the hysteretic nonlinear relationship between matric suction $(\psi)$ and the volumetric water content $(\theta)$ of unsaturated soils. In unsaturated soils where the voids are filled with both water and air, the SWCC describes the volume of the voids that remain filled with water as the soil drains pore solution. The SWCC has been identified as the key soil information required for the analysis of seepage, stability, and volume change problems involved in unsaturated soils.

\subsubsection{Previous SWCC Measurements}

Schaap et al. (2001) [10] evaluated the unsaturated flow parameters of 12 textural classes of soil of the USDA textural triangle, and Tuller et. al (2004) [11] determined the same for some classes from the Unsaturated Soil Hydraulic Database (UNSODA). The residual water content, saturated water content, $\alpha$, and $\mathrm{n}$ for clay samples were tabulated as $0.098,0.459,0.015$, and 1.25 respectively by the former, whereas the same parameters were reported to be $0.102,0.51,0.021$, and 1.20 respectively by the latter. However, researchers did not attempt to take into account for both the laboratory and field-based SWCC parameters. Alam et al. (2017) [12] studied both field and lab-scale SWCC parameters and carried out percolation analysis in vegetated lysimeter in top cover soil of landfill. The values of $\alpha, \mathrm{n}$, and $\mathrm{m}$ were stated as $0.0031,1.6$, and 0.375 , respectively, from the laboratory testing using Tempe cell and dewpoint potentiometer while it was $0.02,1.52$, and 0.3421 respectively as obtained from field soil water characteristic curve (FSWCC). The values obtained from two curves varied highly, as can be seen from the value of $\alpha$, as stated above. Another study by Alam et al. (2019) [13] reported that $\alpha$ value increased 41 times than the initial as-built condition. Therefore, more investigation on the field generated SWCC is required to capture its effect on the numerical modeling output.

\subsubsection{Test Site}

One test site was instrumented near Dallas, Texas, along state highway (SH) 342 with moisture and suction sensors (Fig. 1). The pavement was built on expansive soils in the semi-arid region. A series of moisture and suction sensors were installed at different depths for observing soil response due to climatic events. Industry grade sensors produced by METER Group were used during the study. The sensors were set to yield hourly data connected to the data logger. During installation, soil samples were collected for basic soil testing. The soil was found to be expansive highly plastic clay $(\mathrm{CH})$ with more than $85 \%$ fines. Further, tests were conducted for determining unsaturated soil parameters.

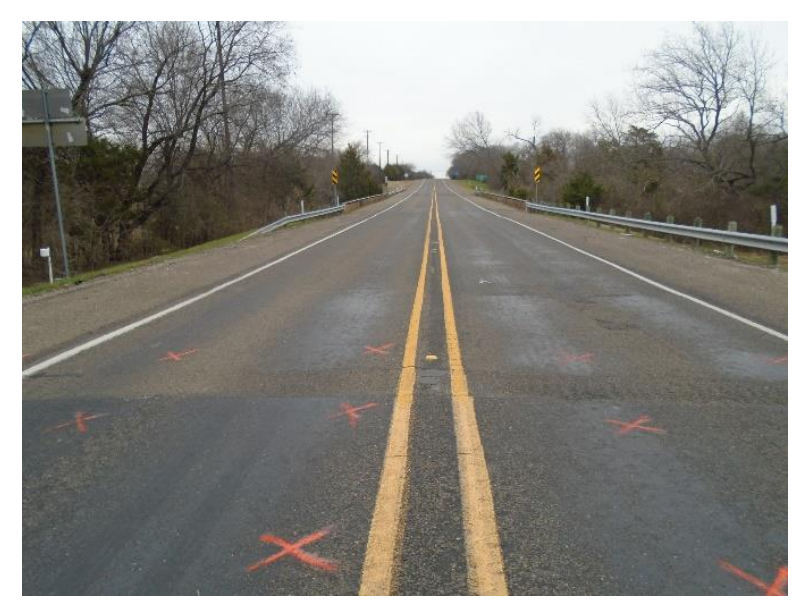

Fig. 1. State Highway 342 near Dallas, Texas, USA

\subsubsection{Instrumentation Details}

Moisture and suction sensors (tensiometer) were installed at the center and edge of the pavement (Fig. 2). Previous researchers have demonstrated the active zone in Dallas region of Texas has high plastic clay up to a depth of 15 $\mathrm{ft}$. As such, the sensors were installed up to $15 \mathrm{ft}$. depth. Soil borings were conducted to install the sensors in the subgrade. Once the sensors were installed at the desired depth, native soil was used to backfill and compact the borehole. Finally, the instrumented segment of the pavement was repaved. One tipping bucket rain gauge was also installed at the side of the pavement in order to record the precipitation events. For this manuscript, only moisture and suction data from different sensors were plotted to determine the field SWCC.

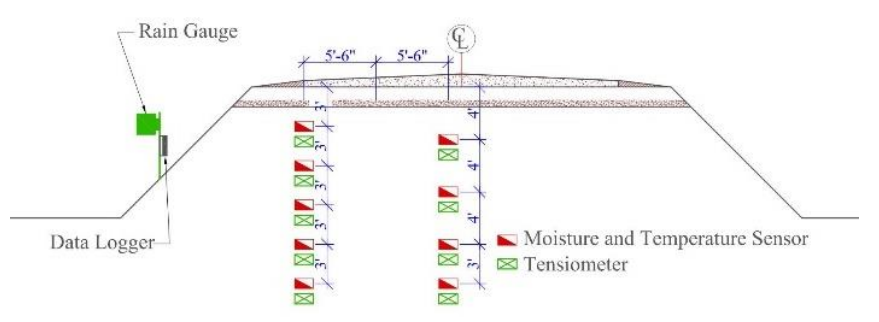

Fig. 2. Field instrumentation at pavement subgrade 


\subsubsection{SWCC Values in this Study}

The current study has been carried out using WP4C Dewpoint Potentiometer manufactured by Decagon Devices Inc., which uses the chilled mirror hygrometer technique and measures the matric suction in a relatively short period of time. The device takes several readings until the pre-determined tolerance is reached under 'precious' mode. It requires approximately 15-20 minutes to record a value and obtain a complete SWCC. Saturated volumetric moisture content $\left(\theta_{\mathrm{s}}\right)$ was found to be 0.46 based on laboratory investigation. Also, using the Van Genuchten equation [14], the values of shape parameters, $\alpha\left(=0.06 \mathrm{kPa}^{-1}\right)$, and $\mathrm{n}(=1.8)$ were determined.

Since the determined laboratory parameters do not address all kinds of heterogeneity present in the field, FSWCCs were used based on the field instrumented sensors and tensiometers to obtain more realistic values. A similar approach adopted by Alam et al. (2017) [12] was used in the current study. The author determined three curves in total with the help of field-based SWCC in vegetated lysimeter; upper bound, lower bound, and the average. Figure 3 shows the FSWCC curve obtained from the instrumented pavement, and the data from each of these curves were fitted with van Genuchten's equation [14].

$$
\theta=\theta_{r}+\left(\theta_{s}-\theta_{r}\right)\left\{\frac{1}{1+(\alpha \psi)^{n}}\right\}^{m}
$$

Where, $\psi=$ soil suction (tensiometer data), $\theta=$ volumetric moisture content (moisture sensor data). a and $\mathrm{n}$ are the shape parameters, and $\mathrm{m}=1-1 / \mathrm{n}$. Based on the FWSCC, the saturated $\operatorname{VMC}\left(\theta_{\mathrm{s}}\right)$ and residual $\operatorname{VMC}\left(\theta_{\mathrm{r}}\right)$ were found to be 0.46 and 0.11 respectively. The shape parameters were determined using the average curve in Fig. 3, and the values after fitted with the van Genuchten equation were $\alpha\left(=0.089 \mathrm{kPa}^{-1}\right), \mathrm{n}(=3.8)$, and $\mathrm{m}(=0.74)$. It can be seen that there exist some variation between the fitting parameters determined from field and laboratory SWCC. As discussed earlier, the laboratory results do not consider the heterogeneity and some of the undetermined factors present in the field. For example, the air entry value (AEV) is around $16 \mathrm{kPa}$ from laboratory determination, whereas it is $10 \mathrm{kPa}$ from the field. The field data indicates that moisture movement inside the soil starts earlier than the lab value. It is to be noted that the instrumentation was in expansive clayey soil where desiccation crack can occur after summer. As such, the water movement might start earlier than the suggested value from laboratory determination. Again, it is reflected in the $n$ value also, which describes the slope of the SWCC curve. Field value is indicating a rapid drainage $(n=3.8)$ than the experiment obtained value $(\mathrm{n}=1.8)$. As mentioned about the possibility of having desiccation crack in the clay, the water moved quickly in the field condition which is reflected at the higher $n$ value. Therefore, both laboratory generated SWCC and field SWCC were considered for numerical modeling and accordingly, the fitted parameters were used for the analysis. The difference in the output is discussed in the results section.

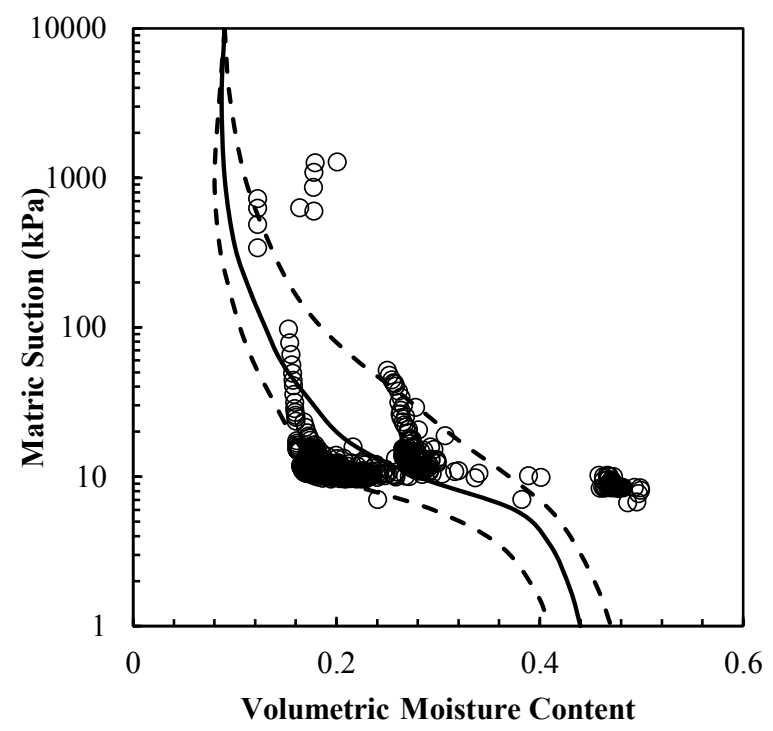

Fig. 3. Field SWCC from SH 342 sensor data

\subsubsection{Predictive Models}

A mathematical equation can be used to best-fit the measured SWCC data. There are numerous best-fit equations proposed by different researchers to estimate the SWCC curve of unsaturated soil (Brooks and Corey 1964 [15]; Brutsaert 1966 [16]; Fredlund and Xing 1994 [17]; McKee and Bumb 1987 [18]; van Genuchten 1980 [14]). Among all the equations, those proposed by van Genuchten (1980) [14] and Fredlund and Xing (1994) [17] give more flexibility to the equation to best-fit the measured data [19]. In this paper, five prediction models were utilized to extract SWCC of soil at a field condition: Saxton et al. (1986) [20], Zapata et al. (2000) [6], Aubertin et al. (2003) [21], Perera et al. (2005) [22], and Ghanbarian et al. (2010) [23]. These models use the regression modeling approach to correlate basic soil properties to a mathematical model. The unsaturated parameters obtained from these five models (Table 1) are described in details in another manuscript (Ahmed et al. 2021, [24]). The authors determined the $\alpha$, $n$, and $m$ values for unsaturated flow analysis from the predictive model. Besides, the same values determined from laboratory and field monitoring are also used in this study.

Table 1. van Genuchten parameters from different predictive models [24]

\begin{tabular}{cccc}
\hline Prediction Models & $\begin{array}{c}\boldsymbol{\alpha} \\
(\mathbf{k P a})\end{array}$ & $\mathbf{m}$ & $\mathbf{n}$ \\
\hline Saxton et al (1986) [19] & 500 & 0.28 & 6 \\
Zapata et al (2000) [6] & 60 & 0.26 & 1.35 \\
Aubertin et al (2003) [20] & 450 & 0.31 & 1.45 \\
Perera et al (2005) [21] & 60 & 0.09 & 1.11 \\
Ghanbarian et al (2010) [22] & 6.1 & 0.16 & 1.19 \\
Ahmed (2017) [25]: Lab & 16 & 0.45 & 1.80 \\
Ahmed (2017) [25]: Field & 10 & 0.74 & 3.80 \\
\hline
\end{tabular}




\subsection{Finite Element Modeling}

In this study, pavement and subgrade have been modeled in GEOSTUDIO software. SEEP/W program has been used to model the rainfall event. Half of the pavement is considered because of the symmetry of the pavement section (Fig. 4). Both the height of the pavement above the natural soil and the width of the half section are considered as $5 \mathrm{~m}$. The slope gradient is considered as $1 \mathrm{~V}: 2 \mathrm{H}$ based on the existing site pavement geometry. The natural soil layer is considered $10 \mathrm{~m}$ thick, and it extends $5 \mathrm{~m}$ outside the foot of the slope. The groundwater table is considered $4 \mathrm{~m}$ below the ground level (Fig. 4). The size of the mesh was $0.5 \mathrm{~m}$ by $0.5 \mathrm{~m}$ quadrilateral and triangles.

\subsection{Boundary Conditions in Numerical Modeling}

For the initial condition of the steady-state analysis, several boundary conditions have been applied. For the groundwater table, a zero pore pressure boundary was applied at the bottom of the model. On the two sides of the model, zero total flux was applied, which restricts water from flowing through the side boundary. Rainfall was simulated using water flux boundary with potential seepage face review. Thus, the pore water pressure at the surface will stay as zero throughout the analysis to avoid any ponding during rainfall at the transient analysis. The boundary conditions and the initial condition of pore water pressure are shown in Fig. 4. For the SEEP/W analysis, an arbitrary rainfall is selected in which the intensity of the rainfall starts from $10 \mathrm{~mm} /$ day, and the duration of the rainfall was 24 hours. After the rainfall event, the change in pore water pressure was observed for seven days.

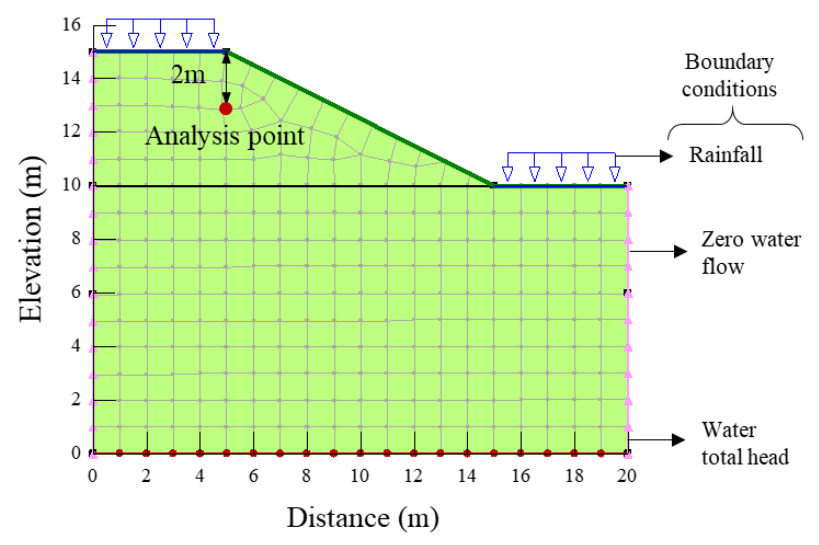

Fig. 4. Schematic diagram of the model in SEEP/W

\section{Results and Discussions}

\subsection{Output from Predictive Models}

Figure 5(a) through 5(e) shows the different output observed from the numerical modeling adopting SWCC parameters from five predictive models. The suction contour after a single rainfall event is plotted in the figure. As can be seen, the suction distribution is different for each predictive model. For better analysis, one single point (as shown in Fig. 4) is selected to observe the variation of the suction with time.

In order to better interpret the different output from the predictive models along with laboratory and field generated values, it is customary to discuss the details of these SWCC parameters. The $\alpha$ value is related to the air entry value (AEV), which corresponds to the suction value when the soil begins to drain water. The higher the $\alpha$ value is, the more difficult it is to drain water out of the soil pores. Saxton et al. (1986) and Aubertin et al. (2003) models have higher $\alpha$ values indicating high suction pressure would require to drain the water. Typically, the sand has a lower $\alpha$ value, whereas clay has the higher as it is related to pore size distribution. Once the soil starts to drain water, it is the slope of the quasi-linear portion of the SWCC curve, which determines the rate at which water drains, which is represented by $n$ value. A lower $n$ value indicates the slow movement of water. In other words, it represents the rate at which the moisture content changes with matric suction. Typically, sand has a higher $n$ value due to its relatively larger pore size.

As can be seen, the change in suction is very low from Perera et al. (2005) predictive model (Figure 5f). The $n$ value from this model was 1.11 , which was the lowest among all the models used. As such, it is expected to have a lower drain rate. On the contrary, a higher drain rate is reported from Saxton (1986) model due to its higher $n$ value of 1.4. It is interesting to see that, in spite of having a higher $n$ value (3.8) from field generated SWCC, the water drain rate was found lower than Zapata et al. (2000) model. It may be due to the lower air entry value $(10 \mathrm{kPa})$ of the field generated SWCC. As the water started to drain early as compared to Zapata model $(60 \mathrm{kPa})$, it reached a value of $27 \mathrm{kPa}$ after seven days, whereas this value was $32 \mathrm{kPa}$ from Zapata model.

\subsection{Comparison of Field and Laboratory SWCC}

In current practice, the SWCC is determined based on the laboratory tests if required for the numerical modeling input. In the current study, a clear distinction is observed between the results obtained from the laboratory generated SWCC and field produced SWCC parameters. Typically, fine-grained soil has a flatter curve compared to coarse-grained soil. In the current study, the field produced SWCC has a higher value of $n$ (3.8) compared to laboratory generated $n$ value (1.8). It can be mentioned that the instrumentation was carried out in expansive soil, which undergoes swelling and shrinkage in the wet and dry season, respectively. It opens some crack in the soil during summer time. Therefore, water moves faster than anticipated. This phenomenon cannot be captured from laboratory testing. Field instrumentation can record this soil behavior, and it is reflected in the higher $n$ value. Again, compaction of soil has an inevitable effect on the water movement, which cannot be captured in the laboratory environment. As can be seen in Figure 5(f), water drains out faster in the field curve than the laboratory one. As such, a higher suction value is reached faster. 
Alam (2017) [26] determined soil water storage for evapotranspiration cover in a landfill using both field and laboratory generated SWCC. The author concluded having a good agreement between field-measured storage and storage obtained from UNSAT-H modeling using field generated SWCC parameters. The author reported of having under and over predicted storage value in the response of various climatic events using the field generated SWCC curves.

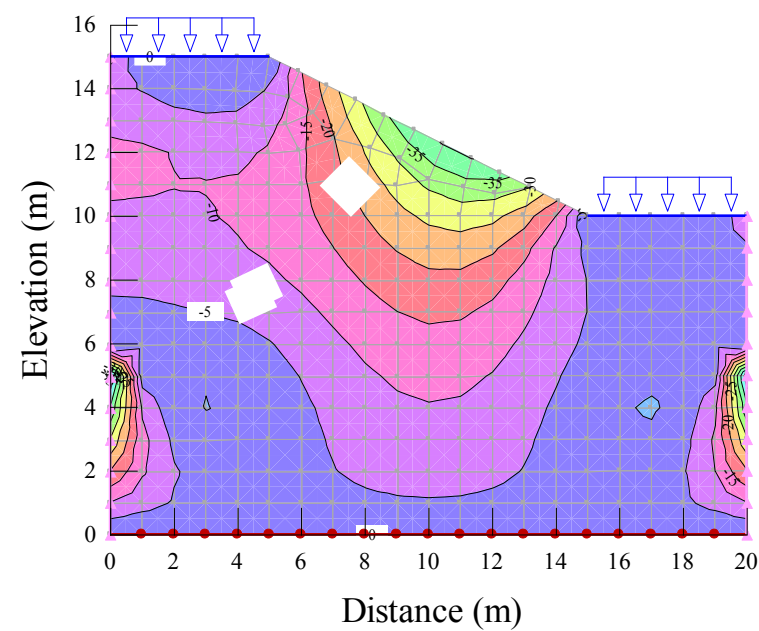

(a)

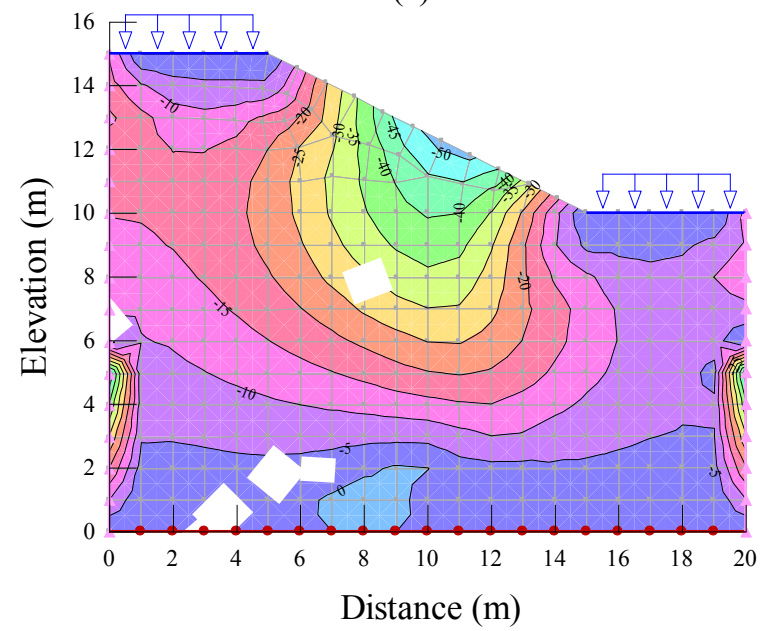

(b)

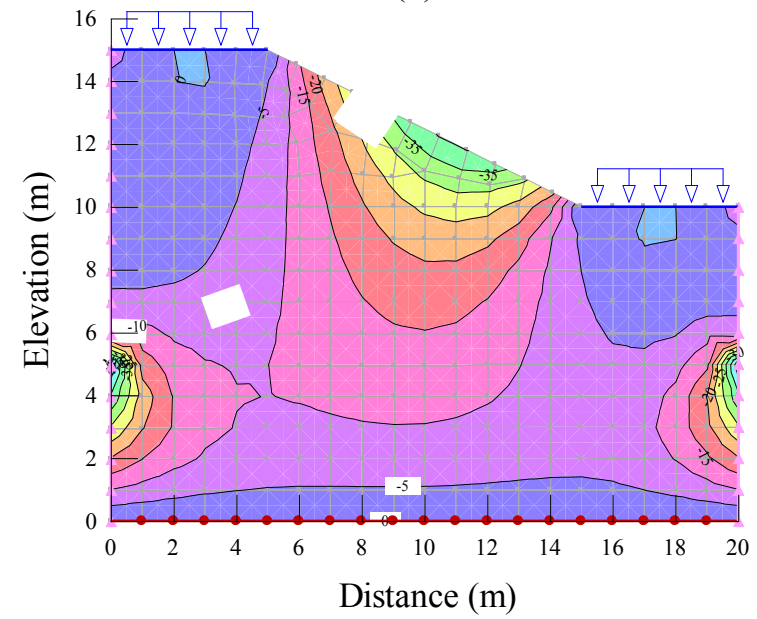

(c)

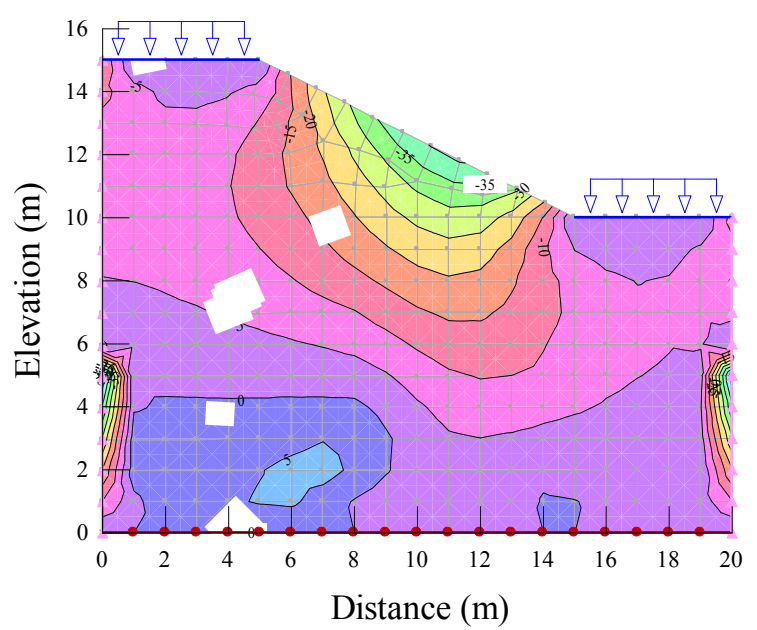

(d)

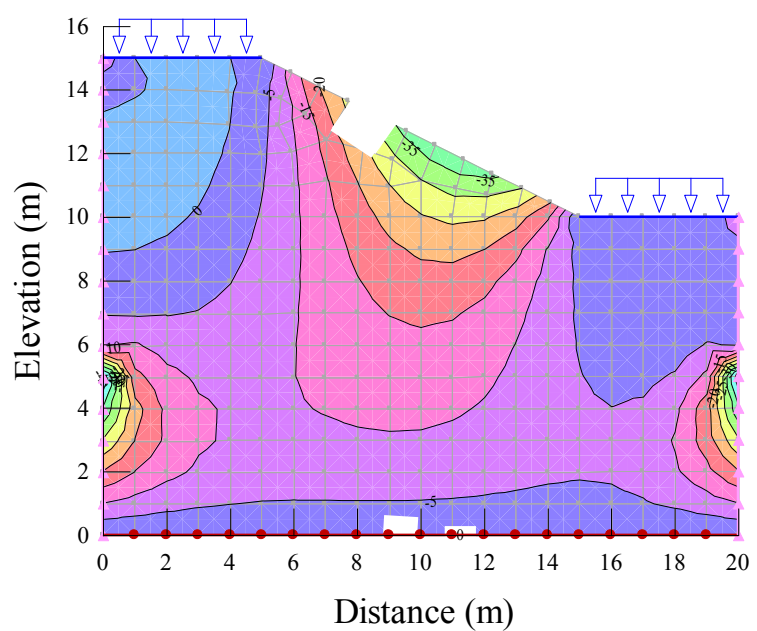

(e)

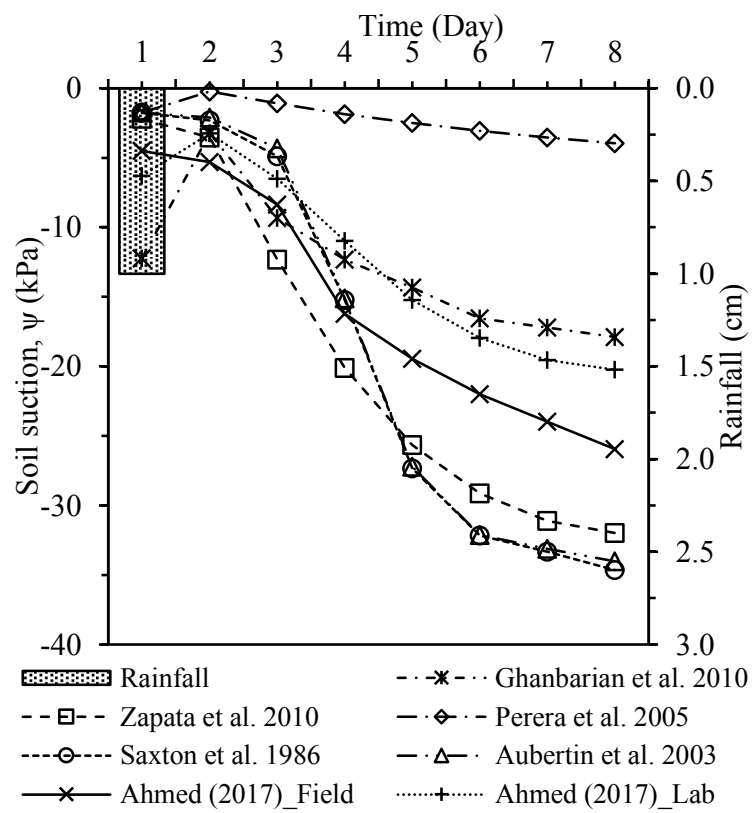

(f)

Fig. 5. Numerical modeling output of suction distribution from the different predictive models (a) Saxton et al. (1986), (b) Perera et al. (2005), (c) Zapata et al. (2000), (d) Ghanbarian et al. (2010), (e) Aubertin et al. (2003), and (f) Comparison of the suction values at $2 \mathrm{~m}$ below the pavement after $120 \mathrm{~mm}$ rainfall after 7 days. 


\subsection{Validation of the Numerical Results}

In order to validate the results obtained from numerical modeling, a comparison was undertaken from real field suction values. Suction is the prime parameter for determining the water movement in soils. Similar instrumentation was carried out at the grass side slope of the same pavement, as shown in Figure 6. Randomly one rainfall event was chosen close to the $10 \mathrm{~cm} /$ day rainfall amount applied in the numerical modeling.

The instrumentation at the side slope was carried out just before summer 2016. A $12.2 \mathrm{~mm}$ precipitation event was recorded on June 2, 2017. From the field sensor data, the suction value varied from $-11 \mathrm{kPa}$ to $-36 \mathrm{kPa}$ in 7 days. It is expected that suction value would rise when there is no precipitation. As such, an increase of $25 \mathrm{kPa}$ of suction value was obtained. This change in the suction pressure was compared with the values obtained from the predictive models with the site and laboratory generated values (Table 2). It can be observed that few predictive models deviated from the original field suction value a lot (Perera and Ghanbarian). In contrast, some of them were close (Saxton, Zapata, and Aubertin model). However, the value obtained from the field generated SWCC matched more closely than any other model.

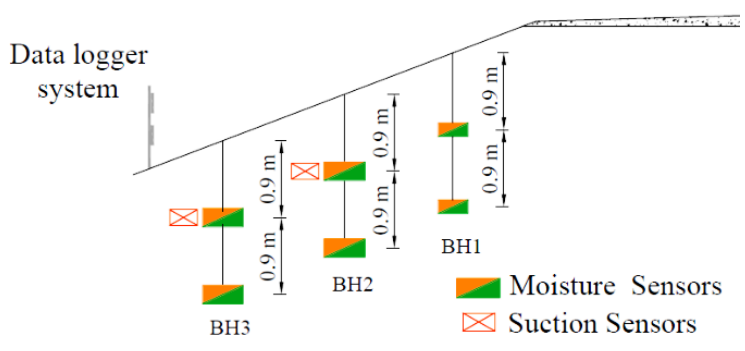

Fig. 6. Instrumentation at pavement side for validation purpose

The reason behind deviation of Perera et al. (2005) and Ghanbarian et al. (2010) model is their relatively lower $n$ value. As the rate of drainage of water is determined by this value, these two model predicted slow movement of water. Therefore, the suction value increased a little after 7 days of the rainfall. Among other models, Saxton et al. (1986) and Aubertin et al. (2003) have very high $\alpha$ value of 500 and $450 \mathrm{kPa}$ respectively. These high values indicate the timing of air entry inside the clay soil. If the water enters late, it will have a significant effect on the movement inside the soil. The closest match apart from the field model was Zapata et al. (2000). This particular model has neither too higher nor lower $\alpha$ value and a moderate $n$ value indicating a smooth drainage. However, the unsaturated parameters obtained from the field instrumentation yielded numerical modeling output closer to real life data. Therefore, any transient seepage and flow analysis require the SWCC parameters determined from field instrumentation for better capture of the field variation. It has the potential to capture the inconsistency in the compaction status also. Lower compaction would trigger for quick movement of water.
Table 2. Change in suction values after 7 days

\begin{tabular}{cccc}
\hline Prediction Models & Initial & Final & Change \\
\hline Saxton et al (1986) & 2 & 35 & 33 \\
Zapata et al (2000) & 2 & 32 & 30 \\
Aubertin et al (2003) & 1 & 34 & 33 \\
Perera et al (2005) & 1 & 4 & 3 \\
Ghanbarian et al (2010) & 12 & 17 & 5 \\
Ahmed (2017): Lab & 6 & 20 & 14 \\
Ahmed (2017): Field & 4 & 27 & 23 \\
\hline
\end{tabular}

\subsection{Limitations of the Study}

The study used field generated SWCC curve data for numerical modeling. The obtained data are useful; however, more interpretable results could be obtained if the monitoring period was prolonged up to several years. Determination of unsaturated parameters from WP4C device has limitations in low suction level. During the numerical modeming, the rainfall was not provided on the slope as there were large trees covering the face of the slope hindering direct infiltration of rainwater to the slope. Suction contributed by tree roots was neglected during the study.

\section{Conclusion}

The manuscript used five other predictive models and laboratory-generated SWCC parameters in numerical modeling to compare the results. Field instrumentation was carried out on a State Highway (SH 342) near Dallas, Texas, USA, with moisture and suction sensors. Model output was validated and compared using another field instrumentation data. The summary of the findings of the study are:

1. There were differences recorded between the values obtained from the laboratory testing and field. van Genuchten parameters were $\alpha\left(=0.089 \mathrm{kPa}^{-1}\right), \mathrm{n}$ $(=3.8)$ and $\mathrm{m}(=0.74)$ from field, whereas these were $0.06 \mathrm{kPa}^{-1}, 1.8$, and 0.45 , respectively.

2. SWCC parameters were also obtained from five other predictive models. A wide range of variations of the $\alpha$ values was observed (from 6 to $500 \mathrm{kPa}$ ) for the same soil. A similar variation was also observed for $n$ parameter (1.1 to 1.45$)$.

3. Numerical modeling output was found to be different for each model. After $10 \mathrm{~cm}$ of rainfall in one day, the suction value changed differently in the various model after 7 days. Perera et al. (2005) and Ghanbarian et al. (2010) model reported very small change in the suction value due to low $n$ value.

4. One $12 \mathrm{~mm}$ precipitation event recorded suction pressure change of $25 \mathrm{kPa}$ in field instrumentation. The field generated SWCC yielded numerical modeling reported $23 \mathrm{kPa}$ of suction pressure change. 
5. Among the predictive models, Zapata et al. (2000) was close to the field monitoring value. However, the closest match was found from the field value yielded model. Laboratory generated SWCC curve was unable to capture the field heterogeneity such as presence of desiccation crack.

\section{References}

1. A. Ahmed, M. S. Hossain, M. S. Khan, \& A. Shishani. (2018). Data Based Real Time Moisture Modeling in Unsaturated Expansive Subgrade. In PanAm Unsaturated Soils 2017, 158-167.

2. M. Elshaer, M. Ghayoomi, \& J. D. Daniel. (2018). Methodology to evaluate performance of pavement structure using soil moisture profile. Road Materials and Pavement Design, 19:4, 952-971.

3. A. Ahmed, \& M. A. Islam. (2020). Effect of Using Geosynthetics in Mitigation of Freeze-Thaw through Numerical Analysis. In Geo-Congress 2020: Geotechnical Earthquake Engineering and Special Topics, Reston, VA: American Society of Civil Engineers, 436-445.

4. C. Kuo, and C. Huang. (2006). Three-dimensional pavement analysis with nonlinear subgrade materials. J. Mater. Civil Eng., 18:4, 537-544.

5. M. Hedayati, M. S. Hossain, A. Mehdibeigi, \& B. Thian. (2014). Real-time modeling of moisture distribution in subgrade soils. In Geo-Congress 2014: Geo-characterization and Modeling for Sustainability, 3015-3024.

6. C. E. Zapata, W.N. Houston, S.L. Houston, \& K.D. Walsh. (2000). Soil-water characteristic curve variability. ASCE Geotechnical Special Publication 99, Denver, CO, 84-124.

7. Rivera-Hernandez, X. A., Ellithy, G. S., \& Vahedifard, F. (2019). Integrating Field Monitoring and Numerical Modeling to Evaluate Performance of a Levee under Climatic and Tidal Variations. Journal of Geotechnical and Geoenvironmental Engineering, 145(10), 05019009.

8. M. D. Hashem, \& A. M. Abu-Baker. (2013). Numerical modeling of flexible pavement constructed on expansive soils. Eur. Int. J. Sci. Tech., 2:10, 19-34.

9. A. Djellali, O. Abdelhafid, \& S. Behrooz. (2012). Behavior of flexible pavements on expansive soils. Int. J. of Transp. Eng., 1:1, 1-14.

10. M. G. Schaap, F. J. Leij, \& M. T. Van Genuchten. (2001). Rosetta: A computer program for estimating soil hydraulic parameters with hierarchical pedotransfer functions. J. of Hydrol., 251:3-4, 163176.

11. M. Tuller, \& D. Or. (2004). Retention of water in soil and the soil water characteristic curve. Encyclopedia of Soils in the Environment, 4, 278-289.

12. M. J. B. Alam, M. S. Hossain, A. Ahmed, \& M. S. Khan. (2017). Comparison of Percolation of Flat and Slope Section Vegetated Lysimeters Using Field Soil
Water Characteristic Curve. In PanAm Unsaturated Soils 2017, 28-37.

13. Alam, M. J. B., and Hossain, M. S. (2019, March). Evaluation of Post-Construction Changes in Soil Hydraulic Properties through Field Instrumentation and In Situ Testing. In Geo-Congress 2019: Geotechnical Materials, Modeling, and Testing (pp. 722-732). Reston, VA: American Society of Civil Engineers.

14. M. T. Van Genuchten, (1980). Closed-form equation for predicting the hydraulic conductivity of unsaturated soils. Soil Sci. Soc. Am. J. 44, 892-898.

15. R. H. Brooks, \& A. T. Corey. (1964). Hydraulic properties of porous media. Am. Soc. Agric. Eng. Trans, 7, 26-28.

16. W. Brutsaert. (1966). Probability laws for pore-size distributions. Soil Sci. 101, 85-92

17. D. G. Fredlund, \& A. Xing. (1994). Equations for the soil-water characteristic curve. Can. Geotech. J. 31, 521-532

18. C. R. McKee, \& A. C. Bumb. (1987). Flow-testing coalbed methane production wells in the presence of water and gas. Soc. Pet. Eng. (SPE) Form. Eval. 2:04, 599-608

19. E. C. Leong, \& H. Rahardjo. (1997). Review of soilwater characteristic curve equations. J. Geotech. Geoenviron. Eng. 123, 1106-1117.

20. K. E. Saxton, W.J. Rauls, J.S. Romberger, \& R.I. Papendick (1986). Estimating generalized soil-water characteristics from texture. Soil Sci. Soc. Am. J., 50:4, 1031-1036.

21. M. Aubertin, M. Mbonimpa, B. Bussiere, \& R.P. Chapuis. (2003). A Physically-based model to predict the water retention curve from basic geotechnical properties. Can. Geotech. J. 40:6, 1104-1122.

22. Y. Y. Perera, C.E. Zapata, W.N. Houston, \& S.L. Houston. (2005). Prediction of the soil-water characteristic curve based on grain-size-distribution and index properties. ASCE Geotechnical Special Publication, 130, Reston, VA, 49-60.

23. A. B. Ghanbarian, A. Liaghat, G.H. Huang, \& M. Th. Van Genuchten. (2010). Estimation of the Van Genuchen soil water retention properties from soil textural data. Soil Sci. Soc. China 20:4, 465.

24. Ahmed, A., Alam, M. J. B., Pandey, P., and Hossain, M. S. (2021). "Determination of Unsaturated Flow Parameters and Hysteresis Curve from Field Instrumentation". Full paper submitted in 3rd PanAmerican Conferences on Unsaturated Soils.

25. A. Ahmed. (2017). Effects of Climatic Loading in Flexible Pavement Subgrades in Texas, Doctoral dissertation, Department of Civil Engineering, The University of Texas at Arlington.

26. M. J. B. Alam. (2017). Evaluation of Plant Root on the Performance of Evapotranspiration (ET) Cover System, Doctoral dissertation, Department of Civil Engineering, The University of Texas at Arlington. 